\title{
Mahidol Scoring for Assessing Various Grades of $\beta$ Thalassemia Intermedia
}

\author{
Jovaria Mannan1, Muhammad Naveed² and Saher Gul Ahdi ${ }^{3}$
}

\begin{abstract}
Objective: To determine the effectiveness of Mahidol Scoring for assessing various grades of $\beta$ thalassemia intermedia. Study Design: Cross-sectional study.

Place and Duration of Study: Fatima Memorial Hospital, Shadman, Lahore, from August 2016 to August 2017.

Methodology: A total of 150 patients, both inpatient and outpatient diagnosed as thalassaemia intermedia fulfilling inclusion criteria, were enrolled, interviewed and examined after an informed consent. All patients were assessed by using Mahidol Scoring system. Their scores were documented on a predesigned evaluation porforma. Patients were labelled as mild, moderate or severe diseased.

Results: In a total of 150 patients, $88(58.7 \%)$ were males and $62(41.3 \%)$ were females. Using Mahidol Scoring, 88 $(58.7 \%)$ were labelled as mild, $53(35.3 \%)$ as moderate and $9(6 \%)$ as severe diseased. Patient who were labelled as mild diseased according to Mahidol Scoring, had no blood transfusions and showed good response to hydroxyurea. Patients with moderate score, were infrequently transfused and showed variable response to hydroxyurea. Patients in severe group received first transfusion at an early age, maintained lower $\mathrm{Hb}$ levels, showed growth retardation, splenomegaly, and had poor response to hydroxyurea.

Conclusion: Mahidol Scoring system is an easy, safe and effective way for classification of thalassaemia Intermedia severity. The grades according to Mahidol Scoring system will aid in the management of patients as the score can be quickly calculated, and can assist the clinician in an initial evaluation for disease severity in patients of thalassaemia intermedia.
\end{abstract}

Key Words: Thalassemia intermedia, Mahidol scoring, Non-transfusion-dependent thalassemia.

\section{INTRODUCTION}

In $\beta$-thalassemia, there is either a complete absence of $\beta$-globin chain production ( $\beta^{0}$-thalassemia) or a partial reduction $\left(\beta^{+}\right.$-thalassemia). Thalassemia minor is heterozygous state and major is homozygous state. Intermedia can be either homozygous or heterozygous and there is substantial clinical overlap between these conditions. ${ }^{1} \beta$ thalassemia intermedia patients can be completely asymptomatic until first or second decade of life, experiencing only mild anemia, minimal splenomegaly without transfusion or requiring occasional blood transfusions during acute infections, stress or blood loss. These patients come under the umbrella of nontransfusion-dependent thalassemias (NTDT).

NTDT is a term used to label patients who do not require regular transfusions for survival, although they may

1 Department of Pediatrics, Fatima Memorial Hospital, Lahore, Pakistan

2 Department of Pediatrics, University College of Medicine and Dentistry, The University of Lahore, Pakistan

3 Department of Pediatrics, Combined Military Hospital (CMH), Lahore, Pakistan

Correspondence: Dr. Muhammad Naveed, Department of Pediatrics, University College of Medicine and Dentistry, The University of Lahore, Pakistan

E-mail: naveed_khaleeque@hotmail.com

Received: September 24, 2018; Revised: February 01, 2019; Accepted: March 07, 2019 require occasional or even frequent transfusions in certain clinical settings and for defined periods of time. ${ }^{2}$ NTDT encompasses three clinically distinct forms: $\beta$-thalassemia intermedia, mild/moderate/hemoglobin $\mathrm{E} /$ $\beta$-thalassemia, and $\alpha$-thalassemia intermedia (hemoglobin $\mathrm{H}$ disease). ${ }^{3}$

Hemoglobin $E / \beta$-thalassemia currently affects around $1,000,000$ people worldwide. 4 It is the commonest haemoglobinopathy in Thailand, India, Laos and Cambodia, where carrier frequencies may reach as high as $80 \% .5$

Mahidol University devised a scoring system to assess severity of Thal/E disease and named it Mahidol Scoring. This scoring system is based on different parameters which include steady state hemoglobin level, age at disease presentation, age of receiving first blood transfusion, requirement for transfusion, splenic size, growth and development (Table I). The total sum of all scores is then interpreted as follows: mild hemoglobin $E / \beta$-thalassemia (severity score $<4$ ); moderate hemoglobin $E / \beta$-thalassemia (severity score $4-7$ ); and severe hemoglobin $E / \beta$-thalassemia (severity score $>7$ ). ${ }^{6}$

$\beta$-thalassemia is the commonest inherited hematological disorder in Pakistan. It is estimated that around $60-80$ million people in the world carry the thalassemia trait. ${ }^{7}$ Prevalence of thalassemia carriers in Pakistan is 5-8\%; but in targeted family, the carrier rate is $34 \% .{ }^{7}$ This high carrier rate has resulted in substantial number of thalassemia intermedia patients which escape correct 
diagnosis and management. These patients present late without transfusion and often have raised $\mathrm{HbF}$ up to $99 \%$.

This study was conducted to evaluate the effectiveness of Mahidol Scoring for assessing various grades of $\beta$ thalassemia intermedia in Pakistani population, which will help to decide a suitable management plan.

\section{METHODOLOGY}

This study was conducted in Department of Pediatric, Fatima Memorial Hospital, Shadman, Lahore from August 2016 to August 2017. Data collection was started after approval from Ethical Review Board. A total of 150 patients, diagnosed as Thalassaemia intermedia fulfilling inclusion criteria, were enrolled, interviewed and examined after an informed consent. These patients were diagnosed thalassaemia intermedia according to international guidelines, prior to start of study were taking either hydroxyurea or blood transfusion and were on regular follow-up in Fatima Memorial Pediatric Department. Patients with established cardiomyopathy and endocrinopathies like diabetes mellitus, hypoparathyroidism, and hypothyroidism were excluded from the study. All patients were assessed using Mahidol Scoring system and information include: $\mathrm{Hb}$ electrophoresis result at the time of diagnosis, response to hydroxyurea, blood transfusion require-ment, change in blood transfusion frequency after start of hydroxyurea and their scores were documented on a predesigned evaluation proforma. Patients were followed 3- and 6-monthly (Table I).

Response to hydroxyurea was divided into three categories. ${ }^{7}$ Good response was considered as tranfusion independence with final hemoglobin $(\mathrm{Hb})$ $>8.0 \mathrm{~g} / \mathrm{dl}$ in tranfusion dependent patient and a rise in hemoglobin $\geq 2 \mathrm{~g} / \mathrm{dl}$ in tranfusion independent patient. Partial response was transfusion independence with rise in $\mathrm{Hb}>2 \mathrm{~g} / \mathrm{dl}$ but final $\mathrm{Hb}$ of $<8 \mathrm{~g} / \mathrm{dl}$ or reduction in tranfusion frequency by $50 \%$ in tranfusion dependent

Table I: Mahidol scoring system.

\begin{tabular}{l|c|c|c}
\hline Steady-state hemoglobin (g/dl) & $>7$ & $6-7$ & $<6$ \\
$\quad$ Value & 0 & 1 & 2 \\
$\quad$ Score & $>10$ & $2-10$ & $<2$ \\
\hline Age of onset (years) & 0 & 0.5 & 1 \\
$\quad$ Value & $>10$ & $4-10$ & $<4$ \\
Score & 0 & 1 & 2 \\
\hline Age at 1st blood transfusion (years) & & & \\
$\quad$ Value & None/rare & Occasionally & Regularly \\
$\quad$ Score & 0 & 1 & 2 \\
\hline Requirement for transfusion & & & \\
$\quad$ Value & $<4$ & $4-10$ & $>10$ \\
$\quad$ Score & 0 & 1 & 2 \\
\hline Size of spleen (cm) & & & \\
$\quad$ Value & - & $+/-$ &,$+ \mathrm{s} / \mathrm{p}$ \\
$\quad$ Score & 0 & 0.5 & 1 \\
\hline Growth retardation & & \\
$\quad$ Value & & \\
$\quad$ Score &
\end{tabular}

patients and rise in $\mathrm{Hb}$ between 1-2 $\mathrm{g} / \mathrm{dl}$ in tranfusion patients. No response was no rise of $\mathrm{Hb}$ in tranfusion independent or same level of tranfusion dependency in tranfusion dependent patients.

Data was entered and analysed in SPSS version 23. Descriptive statistics were performed on all the variables. All categorical variables were presented in the form of frequencies and percentages. Bar charts were constructed for categorical variables. Quantitative variables were presented in the form of mean \pm standard deviation. Chi-square test was used to see statistical significant association between the variables. P-value $<0.05$ was considered significant.

\section{RESULTS}

Out of 150 patients, $88(58.7 \%)$ were males and $62(41.3 \%)$ were females. Using Mahidol Scoring, 88 (58.7\%) were labelled as mild, $53(35.3 \%)$ as moderate and $9(6 \%)$ as severe disease. Consanguinity was present in 131 (87\%) children in the study group.

Among 150 patients, there were $76(50.7 \%)$ children who were diagnosed as cases of thalassemia intermedia in their early childhood between $1-5$ years. It was followed by $44(29.3 \%)$ children in their infancy, and $19(12.6 \%)$ were diagnosed between age of 6-10 years. However, $11(7.3 \%)$ were diagnosed at age $>10$ years.

There were 74 (49.3\%) children who were transfused for first time in their life at age between 1 - 5 years, followed by $46(30.7 \%)$ at age $<1$ year, $10(6.7 \%)$ patients between age 6-7 years and $5(3.3 \%)$ patients transfused after 10 years of age. However, $15(10 \%)$ were never transfused at the time of registration.

Normal growth pattern was seen in $68(45 \%)$ patient, slight growth retardation seen in $36(24 \%)$ patients and growth retardation seen in $46(30.7 \%)$ patients. Spleen size less than $4 \mathrm{~cm}$ (Mahidol Score 0) in $61(40.7 \%)$ patients, between 4-10 cm (Mahidol score 1) in $63(42 \%)$ patients and greater than $10 \mathrm{~cm}$ (Mahidol score 2) in 26 $(17.3 \%)$ patients.

Among mild group, $16(10.7 \%)$ patients were never transfused, $20(13.3 \%)$ had rare/seldom transfusion, $31(20.7 \%)$ patients were occasionally transfused and $11(7.3 \%)$ were frequently transfused. In moderate group $2(1.3 \%)$ patients were never transfused, $8(5.3 \%)$ patients needed rare transfusion, $19(12.7 \%)$ needed occasional transfusion, $22(14.7 \%)$ patients were frequently transfused. Only $1(0.7 \%)$ patient was occasionally transfused while $8(5.3 \%)$ children with severe scoring were frequently transfused. Overall, $34 \%(n=51)$ children were transfused occasionally ( $p<0.001$ ), (Table II).

According to this study, 53 (35.3\%) children of mild score followed normal growth pattern. In moderate group, 15 $(10 \%)$ children were following normal growth centiles, $20(13 \%)$ were slightly impaired and $18(12 \%)$ were significantly impaired in growth. Whereas, in severe 
Table II: Distribution of $\beta$-thallesemia intermedia in the studied group.

\begin{tabular}{l|c|c|c|c}
\hline Categories & Mild & Moderate & Severe & P-value \\
\hline Requirement of BT & $\mathrm{n}(\%)$ & $\mathrm{n}(\%)$ & $\mathrm{n}(\%)$ & 0.0001 \\
Rare & $20(13.3 \%)$ & $8(5.3 \%)$ & $0(0 \%)$ & \\
Occasional & $31(20.7 \%)$ & $19(12.7 \%)$ & $1(0.7 \%)$ & \\
Frequently & $11(7.3 \%)$ & $22(14.7 \%)$ & $8(5.3 \%)$ & \\
None & $16(10.7 \%)$ & $2(1.3 \%)$ & $0(0 \%)$ & \\
Once & $10(6.7 \%)$ & $2(1.3 \%)$ & $0(0 \%)$ & \\
\hline Change blood requirement & & & & \\
0-20\% & $8(5.3 \%)$ & $15(10 \%)$ & $7(4.7 \%)$ & 0.0001 \\
$21-40 \%$ & $22(14.7 \%)$ & $11(7.3 \%)$ & $2(1.3 \%)$ & \\
$41-60 \%$ & $41(27.3 \%)$ & $24(16 \%)$ & $0(0 \%)$ & \\
$61-80 \%$ & $17(11.3 \%)$ & $2(1.3 \%)$ & $0(0 \%)$ & \\
$>80 \%$ & $0(0.0 \%)$ & $1(0.7 \%)$ & $0(0 \%)$ & \\
\hline Growth & & & & \\
Growth retardation (+) & $11(7.3 \%)$ & $18(12 \%)$ & $8(5.3 \%)$ & 0.0001 \\
No growth retardation (-) & $53(35.3 \%)$ & $15(10 \%)$ & $0(0 \%)$ & \\
Slight growth retardation (+/-) & $24(16 \%)$ & $20(13.3 \%)$ & $1(0.7 \%)$ & \\
\hline Response to hydroxyurea & & & & \\
GR (good response) & $62(41 \%)$ & $23(15.3 \%)$ & $0(0 \%)$ & 0.0001 \\
NR (no response) & $3(2 \%)$ & $12(8 \%)$ & $6(4 \%)$ & \\
PR (partial response) & $23(15.3 \%)$ & $18(12 \%)$ & $3(2 \%)$ & \\
\hline SSHB & & & & \\
$>7$ & $61(40.7 \%)$ & $25(16.7 \%)$ & $4(2.7 \%)$ & 0.036 \\
6-7 & $25(16.7 \%)$ & $28(18.7 \%)$ & $5(3.3 \%)$ & \\
$<6$ & $2(1.3 \%)$ & $0(0 \%)$ & $0(0 \%)$ & \\
\hline Spleen size & & & & \\
$0(<4$ cm) & $44(29.3 \%)$ & $16(10.7 \%)$ & $1(0.7 \%)$ & 0.004 \\
1 ( 4-6 cm) & $26(17.3 \%)$ & $30(20.0 \%)$ & $7(4.7 \%)$ & \\
2 ( >6 cm) & $18(12.0 \%)$ & $7(4.7 \%)$ & $1(0.7 \%)$ & \\
\hline Fetal hemoglobin & & & & \\
Less than 20\% & $5(3.3 \%)$ & $1(0.7 \%)$ & $0(0 \%)$ & 0.502 \\
$20-50 \%$ & $7(4.7 \%)$ & $6(4 \%)$ & $1(0.7 \%)$ & \\
$51-70 \%$ & $14(9.3 \%)$ & $12(8 \%)$ & $2(1.3 \%)$ & \\
$71-90 \%$ & $(12.7 \%)$ & $17(11.3 \%)$ & $3(2 \%)$ & \\
Greater than 90\% & & & & \\
\hline
\end{tabular}

group, none followed normal growth pattern ( $p<0.001)$.

Following Mahidol Scoring, in mild group, 62 (41.3\%) children showed good response to hydroxyurea and 23 $(15.3 \%)$ were partial responders. In moderate group, 23 $(15.3 \%)$ were good responders and $18(12 \%)$ showed partial response. In severe group, 6 (4\%) showed no response, while $3(2 \%)$ showed partial response $(\mathrm{p}<0.001)$.

Following Mahidol Scoring, the documented reduction in need of blood transfusion by $41-60 \%$ seen in $41(27.3 \%)$ children in mild group, 24 (16\%) in moderate group and no reduction in severe group. Similarly, $61-80 \%$ blood transfusion reduction seen in $19(12.7 \%)$ children and among them, 17 patients were from mild group $(p<0.001)$.

Steady state hemoglobin greater than $7 \mathrm{~g} / \mathrm{dl}$ was seen in total $90(60 \%)$ patients. Out of them, $61(40.6 \%)$ were in mild group, $25(16.6 \%)$ in moderate group ( $p<0.036)$. Fetal hemoglobin greater than $90 \%$ was seen in 60 $(42 \%)$ patients, among them, $43(28.7 \%)$ were in mild group (p 0.502).

\section{DISCUSSION}

Thalassemia is an inherited disorder with autosomal recessive mode of inheritance. ${ }^{8}$ According to the study conducted by Roy in India, male patients were 1.6 times as compared to females. ${ }^{9}$ In this study, male predominance is prominent as there were $88(58.7 \%)$ males as compared to $62(41.3 \%)$ females; males were 1.4 times more as compared to females. This is because males tend to receive more care and treatment in local culture.

Mondal has described in his study that high incidence of thalassemia is because of endogamous norms of marriages. ${ }^{10} \mathrm{~A}$ study conducted by Rehman and Ishaq documented $68 \%$ carrier rate in their studies for carrier detection in families with beta thalassemia. ${ }^{11,12}$ Similarly, in this study, $87 \% \quad(n=131)$ children belonged to consanguinous. This has also been established that in a target family, carrier rate is $34 \%$ as compared to $5-8 \%$ in general population. ${ }^{7}$

In a study by Kaddah, $51.7 \%$ children were never transfused. ${ }^{13,14}$ In the present study, only $10.7 \%(n=16)$ were never transfused, one transfusion was given in less than one year in $30.7 \%$ and in $49.3 \%(n=74)$ between 1 - 5 years.

In a study conducted by Shah, once or twice monthly blood transfusions are required in patients from 6-10 years of life $(50 \%)$, while children $>10$ years are required 3-4 times transfusion per month. 15 In this study, children among mild group, frequent transfusions were required by only $11(7.3 \%)$ children. While, $8(5.3 \%)$ children with severe scoring were frequently given blood transfusion. Overall, $34 \% \quad(n=51)$ children in this study were transfused occasionally.

Growth retardation is characteristically seen in patients with thalassemia intermedia and is attributed to anemia and high ferritin levels. ${ }^{16}$ According to Hashemi, short strature has been reported in $65.71 \%$ children suffering from thalassemia intermedia. ${ }^{17}$ However, in this study, the trend was different as $53(35.3 \%)$ children of mild variety followed normal growth pattern. In moderate group, only $15(10 \%)$ children were following normal growth centiles, $17(11 \%)$ were mildly impaired and only $1(0.6 \%)$ was severally impaired.

In a study conducted by Asif, $23 \%$ children showed good response to hydroxyurea, $72 \%$ partial response and only $5 \%$ no response. ${ }^{18}$ In this study, in mild group, 62 $(41.3 \%)$ children showed good response and only 23 $(15.3 \%)$ were partial responders. In moderate group, $15.3 \%(n=23)$ were good responders and $8 \%$ showed no response. In severe group, $4 \%$ showed no response while $2 \%$ showed partial response.

Blood transfusions are required by patients suffering from thalassemia intermedia in order to maintain steady state hemoglobin of $\sim 10 \mathrm{gm} / \mathrm{dl}$. Bradai has documented that there is $50 \%$ reduction in need of blood transfusion 
following hydroxyurea. ${ }^{19}$ This advantage of using less transfusions and its related complications by treating thalassemia intermedia as NTDT are huge. In this study, by using Mahidol Scoring, the documented reduction in need of blood transfusion was $41-60 \%$ in $41(27.3 \%)$ children of mild, $24(16 \%)$ children in moderate and no reduction severe groups. Similarly, $61-80 \%$ reduction in $19(12.7 \%)$ children and $89.4 \%$ among these were from mild group.

In this study, steady state hemoglobin $\geq 6 \mathrm{~g} / \mathrm{dl}$ was seen in $148(81.3 \%)$ children; $40.7 \%$ of these were from mild group. In another studies, Hydroxyurea is believed to increase hemoglobin concentration and; hence, reduces the need of transfusion.20,21

Splenomegaly is a characteristic finding in thalassemia intermedia due to hemolysis, 22 and extra medullary hematopoiesis. A total of 40 patients $(70.2 \%)$ were reported to have splenomegaly in the study by Kaddah. ${ }^{14}$ In this study, $59.3 \%$ children had variable size of spleen. However, spleen size $<4 \mathrm{~cm}$ noticed in 44 $(29.3 \%), 16(10.7 \%)$ and $1(.7 \%)$ in mild, moderate and sever groups, respectively.

\section{CONCLUSION}

Mahidol Scoring system is an easy, safe and effective way for classification of thalassaemia intermedia severity. The grades, according to Mahidol Scoring system, will aid in the management of patients as the score can be quickly calculated, and can assist the clinician in an initial evaluation for disease severity in patients of thalassemia intermedia.

\section{REFERENCES}

1. Cappellini MD, Cohen A, Porter J, Taher A, Viprakasit V, Eds. Guidelines for the management of the transfusion dependent thalassemia. $3^{\text {rd }}$ ed. Nicosia: Thalassemia International Federation 2014; p.12-20.

2. Musallam KM, Rivella S, Vichinsky E, Rachmilewitz EA. Nontransfusion-dependent thalassemias. Haematologica 2013; 98:833-44

3. Weatherall DJ. The definition and epidemiology of non-transfusion-dependent thalassemia. Blood Rev 2012; 26 Suppl 1: S3-6.

4. Olivieri NF, Pakbaz Z, Vichinsky E. Hb E/beta-thalassaemia: A common \& clinically diverse disorder. Indian J Med Res 2011; 134:522-31.

5. Weatherall DJ. Keynote address: The challenge of thalassemia for the developing countries. Ann N Y Acad Sci 2005; 1054:11-7.

6. Sripichai $O$, Makarasara $W$, Munkongdee T, Kumkhaek $C$, Nuchprayoon I, Chuansumrit A, et al. A scoring system for the classification of betathalassemia/ $\mathrm{Hb} \mathrm{E}$ disease severity. $\mathrm{Am} \mathrm{J}$ Hematol 2008; 83:482-4.

7. Ishaq F, Mannan J, Seyal T, Abid H, Hassan S. Efficacy and side effects of hydroxyurea in patient with thalassemia intermedia. Pak Paed J 2011; 35:8-12

8. Steinberg MH, Forget BG, Higgs DR, Weatherall DJ. Disorders of hemoglobin: Genetics, pathophysiology, and clinical management. 2nd ed. New York: Cambridge University Press, 2009.

9. Roy RN, Shrivastava P, Das DK, Saha I, Sarkar AP. Burden of hospitalized pediatric morbidity and utilization of beds in a tertiary care hospital of Kolkata, India. Indian J Community Med 2012; 37:252-5.

10. Mondal SK, Mandal S. Prevalence of thalassemia and hemoglobinopathy in eastern India: A 10-year high-performance liquid chromatography study of 119,336 cases. Asian J Transfus Sci 2016; 10:105-10.

11. Rehman A. Beta thalassemia prevention and Pakistan. Pak Paed J 2011; 35: 55-62.

12. Ishaq F, Abid H, Kokab F, Akhtar A, Mahmood S. Awareness among parents of $\beta$-thalassemia major patients, regarding prenatal diagnosis and premarital screening. $J$ Coll Physicians Surg Pak 2012; 22:218-21.

13. Galanello R, Origa R. Beta-thalassemia. Orphanet J Rare Dis 2010; 5:11.

14. Kaddah N, Salama K, Kaddah AM, Attia R. Epidemiological study among thalassemia intermedia pediatric patients. Med $\mathrm{J}$ Cairo Univ 2010; 78:651-5.

15. Shah A, Mishra A, Chauhan D, Vora C, Shah NR. Study on effectiveness of transfusion program in thalassemia major patients receiving multiple blood transfusion in transfusion center in western India. Asian J Transfus Sci 2010; 4:94-8.

16. O'Donnell A, Premawardhena A, Arambepola M, Allen SJ, Peto TE, Fisher CA, et al. Age-related changes in adaptation to severe anemia in childhood in developing countries. Proc Natl Acad Sci USA 2007; 104:9440-4.

17. Hashemi A, Ghilian R, Golestan M, Ghalibaf AM, Zare Z, Dehghani MA. The study of growth in thalassemic patients and its correlation with serum ferritin level. Iranian J Ped Hemat Onc 2011; 1:147-51.

18. Asif N, Anwar T, Chaudary H, Mehmood K, Yaqoob N, Tahir M, et al. Treatment response to hydroxyurea in beta thalassemia. JIMDC 2014; 392:48-52.

19. Bradai M, Pissard S, Abad MT, Dechartres A, Ribeil JA, Landais $\mathrm{P}$, et al. Decreased transfusion needs associated with hydroxyurea therapy in Algerian patients with thalassemia major or intermedia. Transfusion 2007; 47:1830-6.

20. Bordar MR, Silavizadeh S, Haghpanah S, Kamfiroozi R, Bardestani M, Karimi M. Hydroxyurea treatment in transfusion dependent $\beta$ thalassemia patient. Iran Red Creasent Med J 2014; 16:e18028

21. Cokic VP1, Smith RD, Beleslin-Cokic BB, Njoroge JM, Miller JL, et al. Hydroxyurea induces fetal hemoglobin by the nitric oxidedependent activation of soluble guanylyl cyclase. J Clin Invest 2003; 111:231-9.

22. Musallam KM, Taher AT, Rachmilewitz EA. $\beta$-thalassemia intermedia: A clinical perspective. Cold Spring Harb Perspect Med 2012; 2:a013482. 